\title{
Aplicação do princípio da territorialidade ao critério espacial do imposto sobre serviços - ISS
}

\author{
Lorena Mainardes Kossar ${ }^{1}$
}

Rafaela Mattioli Somma ${ }^{2}$

\begin{abstract}
Resumo
A plena compreensão do fenômeno da incidência fiscal somente se demonstra possível mediante a análise de cada um dos componentes da regra que aplicar-se-á ao caso concreto sempre que ocorrer a subsunção da descrição fática do evento tributário à descrição da própria norma, neste contexto denominada regra matriz de incidência fiscal. Tendo em vista a assertiva retro, conclui-se pela grandiosa importância dos critérios material, espacial, temporal, pessoal e quantitativo que da regra matriz de incidência fiscal fazem parte. 0 presente estudo ateve-se à abordagem do Imposto sobre Serviços, sem olvidar da caracterização de cada um dos já referidos critérios e da aplicação dos mesmos ao imposto em comento. Divergências doutrinárias e jurisprudenciais permeiam cada um dos critérios, no entanto, tem-se que grande parte da não pacificidade possui como fundamento a incoerência que paira sobre o critério espacial, cerne do trabal ho que ora inicia-se.
\end{abstract}

Palavras-Chave: Critério espacial; Domicílio; Prestação de serviço; Princípio da territorialidade.

\section{Introdução}

O tema do presente trabalho consiste em uma análise acerca da "Aplicação do Princípio da Territorialidade ao Critério Espacial do Imposto Sobre Serviços - ISS".

A tributação, embora seja um poder estatal legítimo, uma vez que as receitas por meio dela auferidas possibilitam a existência jurídica do Estado e o custeio das atribuições que a própria sociedade Ihe conferiu, está sujeita a uma série de limitações, dentre as quais se destacam os princípios constitucionais tributários.

Ao estudar o ISS, tributo afeto à competência dos Municípios, verifica-se, dentre os diversos pontos polêmicos que gravitam em torno desse tributo, certa dificuldade em definir o critério espacial da hipótese de incidência a ele correspondente, porquanto não há

\footnotetext{
${ }^{1}$ Advogada, graduada pela Universidade Estadual de Londrina em 2007.

${ }^{2}$ Mestranda em Direito Negocial pela Universidade Estadual de Londrina, pós graduada em Direito Tributário Internacional pela Universidade de Barcelona e graduada pela Universidade Estadual de Londrina em 2007.
} 
consenso se este seria o "domicilio do prestador de serviço" ou, de outra sorte, seria o "local da efetiva prestação do mesmo".

Tal situação acaba por gerar considerável insegurança jurídica aos sujeitos passivos da obrigação tributária, uma vez que, na maioria das legislações municipais, tem-se optado por combinar os dois critérios, o que por sua vez só vem a fomentar o fenômeno do excesso da carga tributária, que, há anos, acarreta reflexos negativos na experiência econômica do país,

No espeque de solucionar a questão, partindo-se da premissa que, tecnicamente, ela se constitui em um conflito travado entre as normas de comportamento estabelecidas pelas legislações municipais, optou-se por proceder sua análise à luz das normas de estrutura trazidas pelo texto constitucional, já que aquelas têm por destinatário o produtor das normas de comportamento.

Nesse viés, o presente estudo se desenvolverá a partir da análise da estrutura da norma de incidência fiscal do ISS, à luz da Teoria da Regra-M atriz, idealizada pelo Professor Paulo de Barros Carvalho, para que se possa, num primeiro momento, identificar onde se insere a problemática, ao que se seguirá as considerações propriamente ditas acerca da forma com que dá a aplicação do "princípio da territorialidade" para definir o critério material da hipótese no âmbito dessa espécie tributária.

\section{Regra-matriz de incidência fiscal}

Antes de abordar a problemática que inspira o presente trabalho, faz-se necessário tecermos breves considerações acerca dos elementos que compõem a norma de incidência fiscal do Imposto sobre Serviços (ISS), tendo por base os ensinamentos do professor Paulo de Barros Carvalho no bojo da Teoria da Regra-Matriz (BARROS, 2003).

Num primeiro momento, cumpre lembrar que a regra-matriz de incidência fiscal traz a estrutura sintática das normas jurídicas tributárias em sentido estrito (BARROS, 2003), a qual segue a composição das normas jurídicas em geral, apresentando antecedente e conseqüente, que correspondem, em ordem respectiva, à hipótese tributária e à relação jurídica tributária.

Segundo o professor Paulo de Barros (BARROS, 2003), "a hipótese trará a previsão de um fato, enquanto a consequêencia prescreverá a relação jurídica tributária". 
Em assim sendo, temos, em síntese, que a regra-matriz da norma jurídica tributária constitui-se da hipótese tributária, a qual se compõe pela cognição dos critérios material, espacial e temporal; e pela relação jurídica tributária, a qual, por sua vez, estabelece-se mediante a identificação do critério pessoal, composto por sujeito ativo e passivo, bem como do critério quantitativo, cujos elementos são a base de cálculo e a alíquota.

Assevere-se, ainda, que a importância da teoria da regra-matriz reside no fato de que seus elementos encontram-se, não raro, esparsos pelos diversos diplomas existentes no ordenamento jurídico. Assim, a estrutura por ela apresentada agrega eficiência à atividade do cientista do Direito, sujeito ao qual incumbe a construção da norma jurídica tributária.

Compreendido isso, passa-se à construção da norma de incidência fiscal própria do ISS, tendo por base os diplomas legais concernentes a essa espécie de tributo.

Vale registrar que, em se tratando de tributo, primeiramente, deve-se recorrer à vontade do legislador constitucional, uma vez que tão-somente este é a quem incumbe criar as espécies de tributos, bem como determinar a competência para instituí-los.

A Constituição Federal vigente trata do ISS em seu artigo 156, inciso III e §3oa a seguir transcrito:

Art. 156. Compete aos M unicípios instituir impostos sobre:

III - serviços de qualquer natureza, não compreendidos no art. 155, II, definidos em lei complementar.

$\S 30$ Em relação ao imposto previsto no inciso III do caput deste artigo, cabe à lei complementar:

I - fixar as suas alíquotas máximas e mínimas;

II - excluir da sua incidência exportações de serviços para o exterior.

III - regular a forma e as condições como isenções, incentivos e benefícios fiscais serão concedidos e revogados.

A lei complementar à qual se refere o dispositivo constitucional foi editada recentemente. Constitui-se na Lei no116 de 31 de julho de 2003.

\section{Hipótese tributária}

À luz dos mencionados dispositivos legais identifica-se como critério material da hipótese tributária atinente ao ISS "prestar serviço". Esta é a ação prevista pela Constituição que denota capacidade contributiva, que é o requisito basilar da tributação. 
É importante observar que não é qualquer prestação de serviço que está sujeita a incidência do tributo, uma vez que, para exteriorizar a capacidade contributiva, é imprescindível que aquele seja prestado a um terceiro a título oneroso, ou seja, a mera prestação de serviço para fins particulares, bem como aquela prestada em sede de favor a quem quer que seja não têm a capacidade de gerar renda ao seu prestador, o que, por sua vez, acarreta a inocorrência do primeiro critério da hipótese.

Além disso, há a necessidade do caráter habitual da prestação do serviço, como também sua realização efetiva, haja vista que pelos serviços prestados esporadicamente, e pela mera contratação não se tem por realizado o critério em comento. A especialidade do prestador, de outra sorte, é irrelevante.

No que tange ao critério espacial, que é o local no qual se considera realizado o critério material, pode-se extrair do regramento pátrio que aquele se constitui no local da prestação do serviço.

Todavia, essa questão é bastante divergente na doutrina e na jurisprudência, e principalmente nas legislações municipais, sendo que, por ser o foco do presente trabalho, será abordada em tópico específico.

Passando-se ao critério temporal, que completa a hipótese tributária, constituindose no momento em que se tem por ocorrido o critério material, tem-se que este ocorre quando da efetiva prestação do serviço.

Nesse ponto vale mencionar que pouco importa a data da celebração do contrato, bem como a data em que se obteve o pagamento pelos serviços, tampouco a data determinada para o recolhimento do tributo.

No que se refere a essa última questão, vale mencionar que o momento do recolhimento, diferentemente do critério temporal, não integra a hipótese tributária, mas tão-somente sinaliza a data em que o contribuinte ou responsável pelo pagamento do tributo deve adimplir sua obrigação de pagar, que nada mais é do que um dever instrumental deste. Para que não haja confusão basta observar que, para que seja determinada uma data para o pagamento, é imprescindível que, num momento anterior, a prestação do serviço tenha ocorrido. Assim, critério temporal do ISS jamais será confundido com a data do pagamento deste. 
Superado isso, vale lembrar que o ISS possui uma peculiaridade quando 0 lançamento é efetuado pela autoridade pública (lançamento de ofício), pois, nesse caso, o critério temporal não será a data da efetiva prestação, como em regra, mas, por convenção, ter-se-á por momento da realização do critério material todo primeiro de janeiro de cada ano. Isso ocorre em face da dificuldade do fisco em se fazer presente em todos os momentos nos quais se dá a efetiva prestação do serviço.

Relação jurídica tributária

Ocorrida a hipótese tributária do ISS, ou seja, prestado o serviço, em dado espaço e momento já vistos, deflagra-se a relação jurídica tributária, composta pelo critério pessoal, que corresponde ao sujeito ativo e sujeito passivo, seguido do critério quantitativo, formado pela base de cálculo e alíquota.

Com relação ao sujeito ativo, ou seja, o credor do tributo em análise, tem-se que são os Municípios e o Distrito Federal, uma vez que nenhum destes delegou a atividade arrecadatória a nenhum outro ente público nem privado (parafiscalidade).

Note-se que é imprescindível, nesse ponto, não confundir competência tributária com capacidade tributária ativa. Primeiramente, apresentam-se os sujeitos que possuem competência tributária, que é a capacidade determinada pela Constituição para legislar instituindobo tributo. Todavia, nada impede que, no momento em que o façam, aqueles sujeitos atribuam capacidade tributária ativa a outro ente público ou privado qualquer, pois esta denota unicamente a capacidade para cobrar o tributo. Assim, somente nesse segundo momento é que se define o sujeito ativo da relação jurídica tributária.

No caso do ISS, entretanto, ambos os institutos coincidem na mesma pessoa, pois, como mencionado acima, os credores desse tributo são as mesmas pessoas que têm competência para instituí-lo.

Vale ressaltar, ainda, que a capacidade de arrecadar o ISS, tendo em vista o critério espacial da hipótese, será, via de regra, do Município dentro do território do qual ocorreu a prestação do serviço. 
Definido, portanto, o sujeito ao qual incumbe efetuar a cobrança do ISS, cumpre investigar quem deverá realizar o respectivo pagamento, que nada mais é do que o sujeito passivo da relação jurídica em tela.

A obrigação de pagar o ISS pode recair tanto sobre o sujeito que realiza a prestação de serviços, que será tido como contribuinte, como sobre terceiros, que possuem relação indireta com a prestação do mesmo, sendo, por lei, responsabilizados a recolher o tributo pelos institutos da responsabilidade ou da substituição.

A responsabilidade, em sentido amplo, estatui-se com vistas a garantir a arrecadação, uma vez que em determinados casos o fisco encontra dificuldades em controlar o recolhimento pelo próprio prestador do serviço.

Um exemplo disso são os tributos cobrados do prestador de serviços domiciliados em Município diverso do qual realiza sua atividade. Nesses casos, grande parte das legislações M unicipais obriga o tomador do serviço a reter o ISS na fonte. 0 tomador nessa condição figura como substituto na relação jurídica tributária.

É importante registrar, contudo, que esse instituto surgiu para alcançar os casos extremos em que estejam em jogo a eficiência da arrecadação, não podendo ser utilizado pelo legislador, como vem ocorrendo em diversos Municípios, ao seu bel prazer, uma vez que tal prática não observa o principio da capacidade contributiva, o que somente é tolerável em situações de extrema necessidade.

Note-s, ainda nesse ponto, que, à luz do que dispõe a Constituição Federal em seu artigo 156, inciso II, pode-se ter a impressão de que o sujeito passivo seria aquele que efetua um serviço, independentemente de este fosse prestado.

Ocorre, porém, que, após uma análise um pouco mais cuidadosa, não é difícil perceber que a intenção do constituinte foi abarcar a atividade do prestador de serviços e não somente daquele que exerce um serviço qualquer. Por isso, doutrina e jurisprudência já são pacíficas nesse sentido.

Estabelecida a relação jurídica tributária atinente ao ISS, resta, por fim, a análise do critério quantitativo, que será responsável por definir o valor real do imposto ora explorado.

Para dar início ao cálculo, é primordial que se defina uma base de cálculo sobre a qual incidirá a alíquota. Para tanto, impera-se ter em mente que esta é a responsável por medir em termos pecuniários a capacidade contributiva. Enquanto o critério material 
exterioriza que determinados indivíduos possuem tal capacidade, a base de cálculo determina o seu valor patrimonial.

Dentro desses limites, alguns Municípios fixam alíquota única e outros alíquota variável de acordo com o critério da seletividade, levando-se em conta a imprescindibilidade do serviço para a sociedade.

Ao final dessa análise acerca da norma de incidência fiscal do ISS, conclui-se, em síntese, que o tributo estudado se constitui, via de regra, em um imposto incidente sobre a prestação de serviços realizada no âmbito municipal, no momento de sua prestação ou em todo primeiro dia de cada ano, devido pelo seu prestador, ao Município em que se deu a prestação, cujo cálculo se efetua com base no valor do serviço, sobre o qual incidirá uma alíquota que pode, a critério do Município, variar entre $2 \%$ e $5 \%$.

\section{Critério espacial da hipótese tributária do imposto sobre serviços}

Entende-se por critério espacial o local onde ocorre o evento, onde se considera realizado o critério material da hipótese tributária.

Considerando o já exposto acerca do critério material da regra matriz de incidência fiscal do ISS, extrai-se que este consiste na efetiva prestação do serviço.

Integrando o conhecimento vertido nos dois parágrafos anteriores poder-se-ia, desde um primeiro momento, e sem a análise mais acurada da situação, que terá palco no próximo item, asseverar que o critério espacial da hipótese tributária do imposto sobre serviço é o local em que, efetivamente, ocorreu a prestação do serviço.

Conflito estabelecido entre o domicílio e o local de prestação do serviço

Analisar o Imposto sobre Serviços (ISS) significa abordar uma imensa gama de questões polêmicas que o envolvem. No entanto, no presente estudo a atenção foi direcionada ao cerne de todo questionamento acerca do ISS, situação esta que, uma vez dirimida, importa na solução ou, pelo menos, melhor visualização de todas as demais.

Tendo em vista que o critério material do ISS é a prestação de serviços, a base de cálculo consiste no preço do serviço prestado. 
Embora 0 ideal fosse tributar pela base de cálculo real, vários prestadores de serviço não emitem nota fiscal. Diante disso, e em face da dificuldade de fiscalização, o fisco, para dadas categorias, preferiu emitir carnê, fixando a base de cálculo, a fim de efetuar, dessa forma, o recolhimento por estimativa.

Por fim, resta tão-somente identificar a alíquota, que consiste na fração da base de cálculo que determinará o valor a ser recolhido a título de ISS.

Ao M unicípio compete fixá-la dentro do limite máximo e mínimo definido pela lei complementar. Assim reza a Constituição, porém a lei complementar somente definiu o limite máximo de $5 \%$, sendo que acerca do mínimo somente se tem uma alíquota provisória de 2\% instituída pela Emenda Constitucional no37/02.

De modo sucinto, cinge-se a problemática a ser abordada à análise do critério espacial que compõe a hipótese tributária do tributo em comento.

No entanto, pode-se afirmar que referida análise dar-se-á em consonância não só com a Lei Complementar que disciplina o ISS no Brasil (LC 116/03), mas também, e, sobretudo, de acordo com o aspecto constitucional que açambarca a questão.

Tem-se, em virtude do disposto no artigo 30 da LC 116/03, que o critério espacial do ISS consiste no local onde se situa o estabelecimento do prestador ou, ainda, o lugar do domicílio do prestador.

Lei Complementar 116/2003

Artigo 30: 0 serviço considera-se prestado e o imposto devido no local do estabelecimento prestador ou, ainda, na falta do estabelecimento, no local do domicílio do prestador, exceto nas hipóteses previstas nos incisos I a XXII [...].

Em que pese a disposição contida no artigo transcrito acima, da análise detida do texto constitucional extrai-se que, em sendo o Brasil uma República Federativa, nele vigem o Princípio da Autonomia dos entes federados, do qual decorre o Princípio da Territorialidade da Federação.

Da exegese do Princípio da Territorialidade da Federação extrai-se que cabe a cada ente federativo tributar os fatos que ocorrem em seu território, ou seja, cada ente federativo exerce competência em um determinado espaço, sendo que os demais entes neste processo não podem interferir. 
Tem-se, destarte, que, muito embora teoricamente a lei tenha determinado que 0 ISS incidirá no local em que se situa o domicílio do prestador de serviço, entre os M unicípios a guerra fiscal continua a ocorrer.

Tal fato encontra fundamento no Princípio já trazido à baila; entretanto, pode-se asseverar que os Municípios continuarão agindo desta maneira, uma vez que, quando da determinação do local em que incidirá o ISS, pautam sua conduta de acordo com seus interesses, ora adotando o princípio da Territorialidade da Federação, segundo o qual o critério espacial do ISS é o local da prestação do serviço, ora o disposto na LC 116/03, que, para tal, adota o domicílio.

Prevalência do princípio da territorialidade da federação

Inconcebível demonstra-se a idéia de que uma Lei Complementar possa infringir princípio constitucional, pelo que, como resposta ao questionamento levantado quando do início do presente estudo tem-se que, indubitavelmente, deve o local da prestação do serviço prevalecer sobre o domicílio quando da análise do critério espacial da hipótese tributária do ISS, porquanto somente desta maneira o princípio constitucional da Territorialidade da Federação será efetivamente observado.

Por fim, cumpre salientar que aos cientistas do Direito resta delegada a missão de fazer com que o disposto no texto constitucional seja implementado e não infringido pelas legislações que o regulamentam.

\section{Conclusão}

O Imposto sobre Serviços, que incide sobre a prestação de serviço no próprio momento em que esse fato ocorreu ou, ainda, em algum outro instante, por determinação legal, consiste em um imposto municipal, o que significa dizer que o sujeito ativo que integra o critério temporal da regra matriz de incidência fiscal do ISS é o M unicípio.

Considerando o fato de que os M unicípios são diversos, existindo, pois, em número significativo, pode-se afirmar que de muitas diferentes formas o ISS será regulamentado, haja vista que cabe ao ente federado que detém competência para instituir o tributo 0 estabelecimento das condições sob as quais processar-se-á a arrecadação do mesmo. 
Fator de grande importância, também responsável por ensejar a análise do tema objeto do presente estudo consiste no fato de que o ISS constitui a maior fonte de receita dos Municípios e, destarte, o interesse econômico que este imposto desperta no ente federativo que detém capacidade tributária ativa com relação à sua arrecadação é de grande vulto.

Desta feita, inequívoca demostra-se a fatídica realidade: os Municípios degladiamse com o fito de imprimir maior volume à sua receita por meio de uma maior arrecadação do ISS e, para tanto, não medem esforços, avançando com muita freqüência, a o âmbito territorial de incidência do ISS de outro Município.

A Corte Suprema de nosso país, entretanto, caminhava no sentido de firmar entendimento que guardava total harmonia com o texto constitucional pátrio, defendendo ser o Município onde ocorreu a prestação do serviço o ente federado ao qual incumbe a cobrança do ISS.

Diz-se em consonância com a Constituição da República, sob a perspectiva ora abordada, a prática de atos que respeitam o princípio da Territorialidade da Federação, segundo o qual cada ente federado possui a prerrogativa de instituir impostos sobre os fatos que ocorrem em seu território.

No entanto, em manifesto retrocesso constitucional, em 2003 entrou em vigor a Lei Complementar 106, que deveria uniformizar a regulamentação do ISS, sem, entretanto, extirpar a competência municipal, de modo a ensejar a diminuição das guerras fiscais travadas entre os M unicípios.

Ocorre que a Lei Complementar 116/03 determinou que o Município responsável pela cobrança do ISS é aquele onde está localizada o domićlilo do prestador de serviço ou o local do estabelecimento deste. Tal fato permite a total ingerência de um Município no território de outro Município, em flagrante desrespeito ao princípio constitucional da Territorialidade da Federação já mencionado.

Diante da lesão à Constituição que se observa quando da análise do determinado pela Lei Complementar 106/03 somente pode-se extrair que a aplicação do ali contido deve ser evitada e incumbe aos estudiosos do fenômeno jurídico a efetiva defesa do diploma pátrio que nos assegura uma existência digna, não permitindo, desse modo, o simples argumento de que existe lei que regulamenta a matéria, pelo que deve o Município onde se 
encontra localizado o domićílio ou estabelecimento do prestador de serviço arrecadar o ISS decorrente dos serviços por este prestados, independentemente do local em que a prestação efetivamente ocorreu.

Há que se pugnar pelo respeito à Constituição da República, traduzida na discussão que ora se finaliza por meio do princípio da Territorialidade da Federação, segundo o qual o Município onde ocorreu a prestação de serviço deve ser o responsável pela arrecadação do ISS.

Para o desenvolvimento e efetiva compreensão do tema aqui abordado foi necessária uma prévia análise de cada um dos critérios que compõem a regra matriz de incidência fiscal do ISS, uma vez que a deteç̧ão da relevância da questão crucial da presente explanação decorreu dessa análise primeira.

\section{Referências}

BRASIL, Constituição da República Federativa do. São Paulo: Saraiva, 2008.

CARVALHO, Paulo de Barros. Curso de direito tributário. 15. ed. São Paulo: Saraiva, 2003. 